\title{
IN-FLIGHT MEASUREMENT OF ICE GROWTH ON AN AIRFOIL USING AN ARRAY OF ULTRASONIC TRANSDUCERS \#
}

\author{
R. John Hansman, Jr. " and Mark S. Kirby ${ }^{*}$ \\ Massachusetts Institute of Technology \\ Cambridge, Mass.
}

\author{
Robert C. Meknight \\ NASA Lewis Research Center \\ Cleveland, Ohio \\ Robert L. Humes ${ }^{++}$ \\ Calspan Corporation \\ Arnold Air Force Station, Tenn.
}

\section{Abstract}

Results of preliminary tests to measure ice growth on an airfoil during flight icing conditions are presented. Ultrasonic pulse-echo measurements of ice thickness are obtained from an array of eight ultrasonic transducers mounted flush with the leading edge of the airfoil. These thickness measurements are used to document the evolution of the ice shape during the encounter in the form of successive ice profiles.

Results from three research flights are presented and discussed. The accuracy of the uitrasonic thickness measurements is found to be within $0.5 \mathrm{~mm}$ of mechanical and stereo photograph measurements of the ice accretion. Ultrasonic measurements show that the ice growth rate is typically not constant, but varies during the flight. For dry ice growth, these variations in the ice growth rate are primarily due to fluctuations in the cloud liquid water content. The experimentally measured ice growth profiles are compared with ice growth predicted by an analytical icing code. Oiscrepancies between these analytical predictions and experimental results highlight the need for a better understanding of the physics of wet ice growth and the effects of varying icing conditions.

\section{Introduction}

Aircraft icing is a dynamic process. Ice accreting on a surface alters the aerodynamic flowfield over the surface, changing both the cloud droplet trajectories and the heat transfer from the surface. Since both the cloud droplet trajectories and the local heat transfer control the resulting ice shape, the dynamic nature of the icing process must be considered if accurate icing models and scaling laws are to be developed.

Two distinct icing regimes, "dry" and "wet" ice growth, have been identified. During dry ice growth the impinging droplets freeze on impact, and the ice surface is dry. Dry, or rime ice growth is

* Assistant Professor, Aeronautics and Astronautics.

- Resiarch Assistant, Aeronautics and Astronautics.

** Pilot and Aerospace Engineer.

++ Research Engineer.

\# AlAa paper 87-0178.

Copyright (C) 1986 by MIT. characteristic of cold cloud temperatures, and low to moderate cloud liquid water contents. If the heat transfer from the accreting surface is insufficient to freeze the impinging cloud droplets, liquid will form locally on the surface, and the ice growth is said to be wet. Wet, or glaze ice growth is typically encountered at warm cloud temperatures close to freezing, and moderate to high cloud liquid water contents.

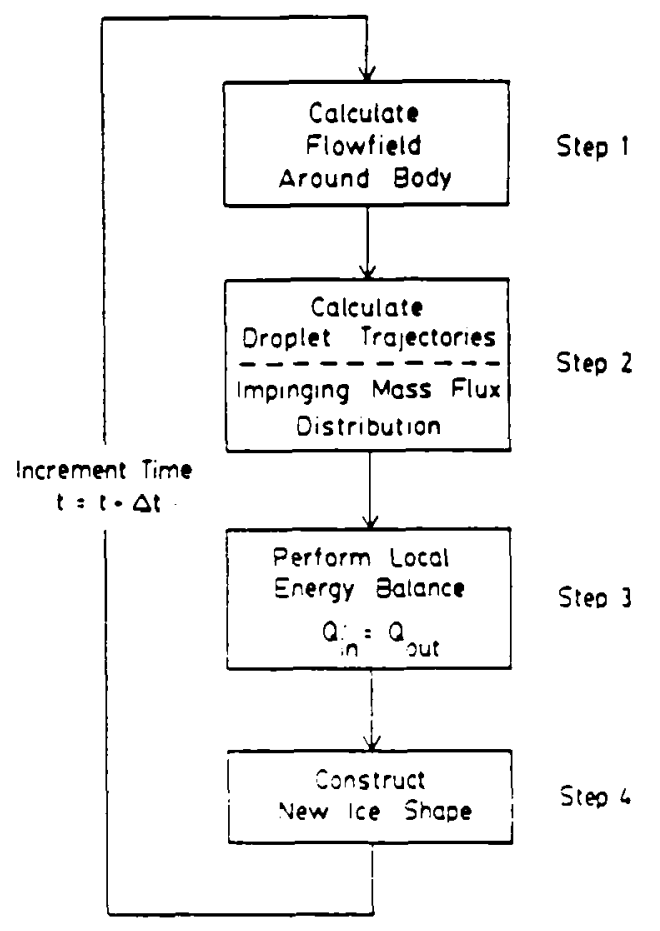

Fig. 1 Schematic breakdown of typical andytical icing model galiulations.

Current analytical icing models le $^{-4}$ typically divide the icing analys is into four na in aroas, as snown in the block diagram in figure 1. First, the flowfield around the surface is computed; the droplet trajectories within the flowfield are then calculated by integrating the droplet equations of motion. This second calculation provides the mass flux distribution (due to the droplets) over the body. The third step involves calculating the heat transfer distribution over the surface and then performing a local snergy balance to determine the 
amount of ice formed. The final step is to construct the new ice shape. By repeating this series of calculations, using the iced geometry for the new flowfield calculation, the dynamic nature of the icing process is analytically simulated.

For dry ice growth conditions, the ice shapes predicted using these analytical models are generally in good agreement with those observed experimentaliy conditions, the analyticaliy predicted ice shapes are often in poor agreement with experimental. results 1,4 . The reasons for this poor agreement are not certain, although the energy balance used by the analytical models has recently received much attention. A better understanding of the ice accretion process has, however, been hampered by a lack of experimental data on ice growth as a function of time.

Experimentally measured ice shape "histories" would permit a detailed comparison of actual icing behaviour with that predicted analytically. Measurements of ice shape as a function of time would allow the aerodynamic factors involved in the accretion process (i.e. flowfield and droplet trajectories) to be isolated from the more complicated thermodynamic processes involved. For example, by analyzing the flowfield associated with the evolving ice shape, the significance of collection efficiency variation with changes in ice shape could be quantitatively determined. This aerodynamic feedback phenomenon, coupled with changes in the heat transfer distribution over the ice surface, are thought to be the controlling factors in the growth of the "horns" characteristic of glaze ice formations.

In addition to providing insight into the physics of the ice accretion process, experimentally measured ice growth histories would also permit a direct, quantitative comparison of the differences between ice growth in flight and wind tunnel icing tests. A better understanding of these differences is essential for the accurate interpretation and application of icing wind tunnel results ${ }^{\circ}$.

Measurement of ice growth in ic ing conditions is difficult. Most current ice accretion instruments relate ice growth on an exposed probe to that on the surface of interest. While these probe-type measurements can provide good time resolution of the icing rate, they cannot provide good spatial resolution of the ice accretion on the remote surface (due to differences in the collection efficiencies and heat transfer distributions for the probe and the surface). Alternatively, mechanical or photographic measurements of the ice accretion can be made at the completion of an icing test. While these "end-point" measurements provide excellent spatial resolution of the accretion, they contain no information about the growth of the ice shape prior to the measurement. Since it is not practical to frequently halt an icing encounter in order to make mechanical or photographic measurements, good time resalution of ice growth is not possible with these types of measurements.

Recently developed ultrasonic techniques for ice thickness measurement ${ }^{7}$ offer the potential for both good time resolution of ice growth as well as good spatial information on the accreted ice shape. The principle of uitrasonic pulse-echo thickness measurement is explained below, and the ultrasonic array approach used to measure ice growth is then outlined.

\section{Ultrasonic Pulse-Echo Thickness Measurement}

Uitrasonic pulse-echo measurement of ice thickness on a surface is accomplished by emitting a brief compressive wave, or pulse, from a small ultrasonic transducer mounted flush with the accreting surface (see figure 2). The pulse travels through the ice, is reflected at the ice surface and then returns to the transducer as an echo signal. The time elapsed, $T_{0-e}$, between the emission of the pulse and the return of the echo from the ice surface can then be used to calculate the ice thickness, $D$, from the formula:

$$
0=C \cdot T_{p-e^{12}}
$$

Where $C$ is the speed of propagation of the pulse-echo signal in ice. In a previous study ${ }^{7}$, the authors found this speed of propagation to be insensitive to different types of ice (glaze, rime and mixed) formed at typical flight airspeeds. A value of $3.8 \mathrm{~mm} / \mathrm{\mu s}$ was used for the speed of sound in ice for all the results presented in this paper.

The ultrasonic pulse-echo technique also allows the presence or absence of 1 iquid water on the ice surface to be uniquely determined by examining the time variations of the echo signals received from the ice surface. This information in turn allows the type of ice growth ocurring, "wet" or "dry", to be discerned.
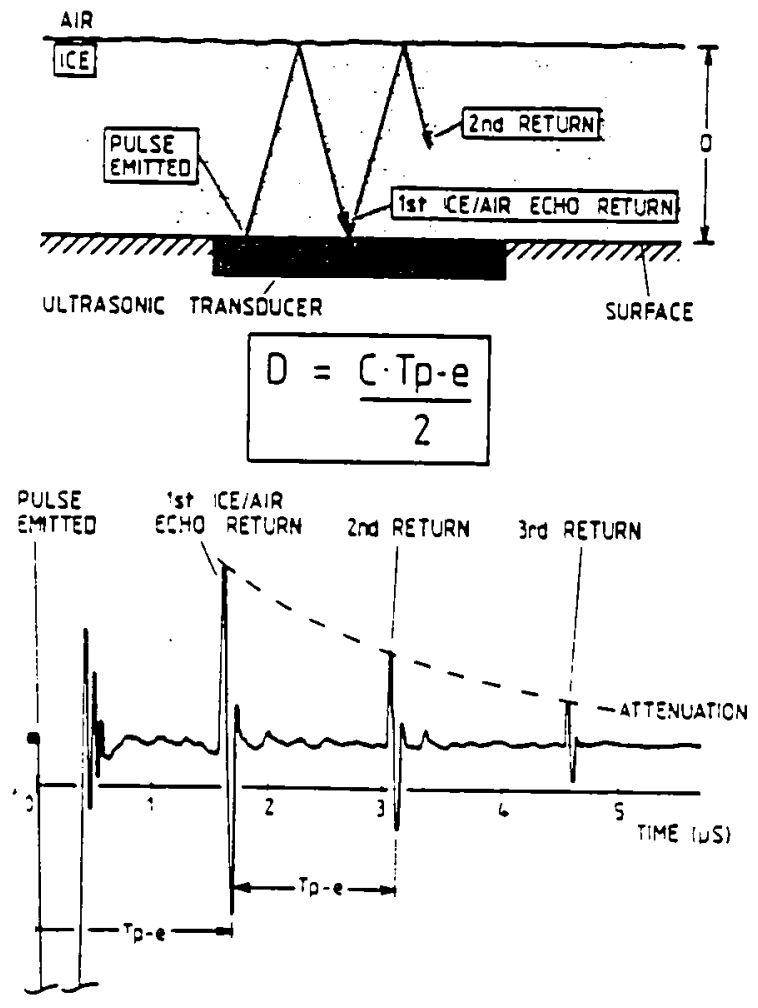

Fig. 2 Ultrasonic pulse-echo thickness measurement and typical ultrasonic pulse-echo signal in ice. 
By frequently emitting pulses (typical repetition rates are several $\mathrm{KHz}$ ), the ultrasonic pulse-echo technique can provide a direct measurement of ice thickness many times a second. If several transducers are grouped in an array, then by interpolating between the individual thickness measurements from each transducer, the ice shape over the array may be measured as a function of time. This paper describes results of prel iminary tests using an array of eight ultrasonic transducers to measure ice growth on the leading edge of an airfoil during flight icing conditions. The primary purpose of these tests was to demonstrate the feasibility of using such an array to document ice growth behaviour as a function of time.

Ice growth measurements made with the ultrasonic array during three research flights are presented in this paper. Ice thickness measurements from the array transducers are used to construct profiles of the ice accretion during the icing encounter. These profiles are related to the ambient atmospheric icing conditions and are also compared with ice growth profiles predicted using an analytical icing code.

\section{Experimental Apparatus}

NASA Lewis Icing Research Aircraft \& Wing Cuff Installation

The aircraft used for flight testing the ultrasonic array was the NASA Lewis Icing Research Aircraft, a De-Havilland DHC-6 Twin Otter. This aircraft is extensively equipped with instrumentation to measure and record the ambient atmospgeric icing conditions encountered in flight. The ultrasonic array was installed in a four foot long OHC-6 airfoil section mounted over the starboard wing of the aircraft at approximately the $3 / 4$ span station (see figure 3). This airfoil section, or wing cuff, protruded approximately three inches forward of the main wing. The wing cuff was constructed of aluminum $0.025^{\prime \prime}$ thick, and was not equipped with any ice protection system.

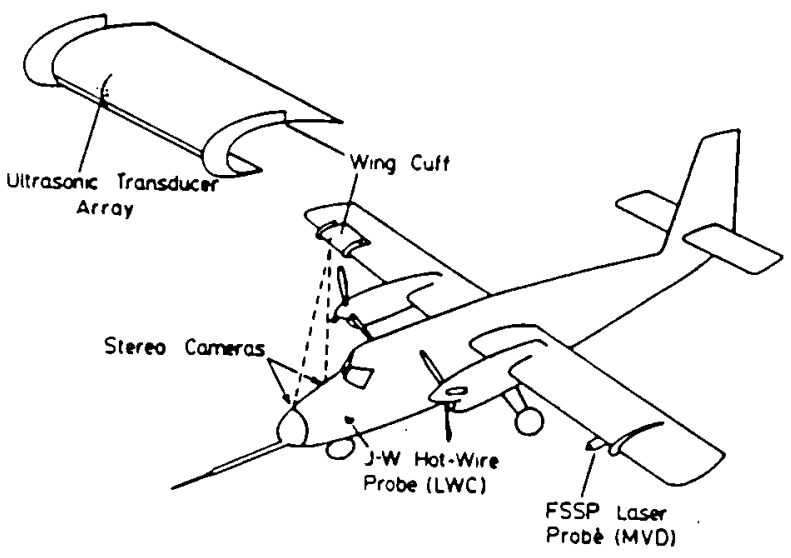

Fig. 3 Wing cuff and ultrasonic array installation on NASA Lewis Icing Research Aircraft (DHC-6 Twin Otter).

\section{Ultrasonic Array}

The array consisted of eight identical $5 \mathrm{MHz}$ ultrasonic transducers mounted flush with the wing cuff surface. The transducers were all located within a 90 degree arc around the leading edge of the wing cuff. The transducer positioning was based on previous stereo photograph measurements of ice formatiops 90 the leading edge of the research a ircraft 10,1 . Due to size constraints only six of the transducers could be placed at the same span station, and two additional transducers were slightly offset ( $\left.0.75^{\prime \prime}\right)$ to provide better ice surface coverage. The eight transducers were of the broadband, heavily damped type, with element diameters of $0.25^{\prime \prime}$. The transducers were mechanically supported in the cuff by a thin doubler plate behind the cuff skin.

\section{Multiplexing Pulser/Receiver}

A multiplexing pulser/receiver unit was used to sequentially excite each transducer in the array (see figure 4). The pulser/receiver section provided the electrical signals necessary to produce the ultrasonic pulse and amplify the return echo, with the multiplexer controlling the active time for each transducer. Typically, the multiplexing rate was set so that each transducer was active for approximately two seconds; four complete "scans" of the array were thus obtained every minute. Eight 40 foot long co-axial cables carried the electrical signals from the wing cuff array to the multiplexing pulser/receiver in the a ircraft cabin.

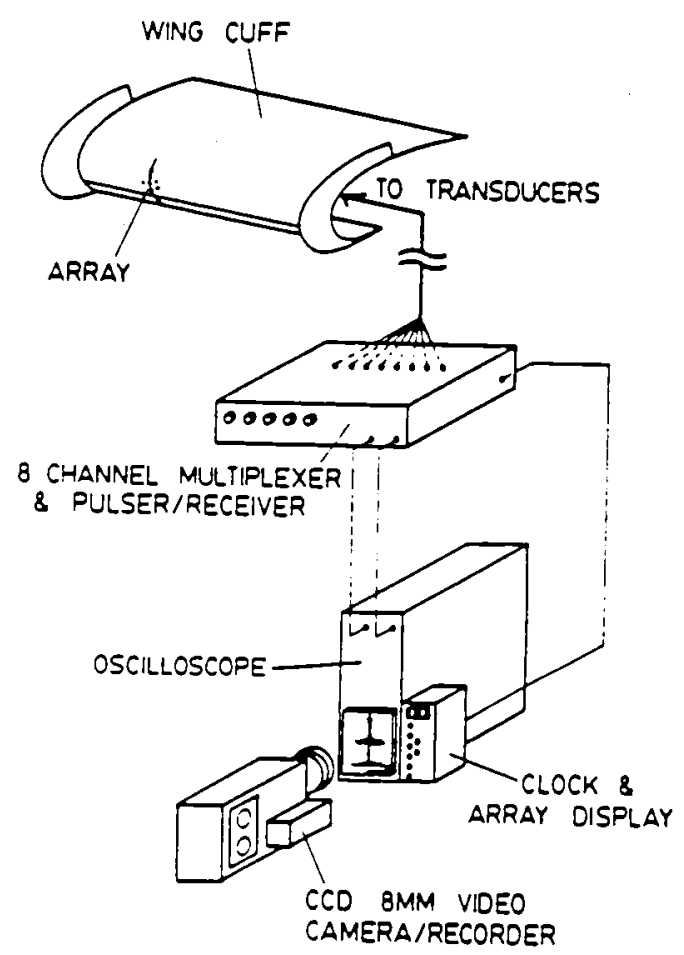

Fig. 4 Schematic of ultrasonic array equipment configuration. 
Oscilloscope/Video Camera

A $60 \mathrm{MHz}$ bandwidth oscilloscope was used to display the uitrasonic echo signal from the active transducer. In order to provide a permanent record of these time-dependent echoes, the oscilloscope display was filmed by a video camera (figure 4). Also within the camera's field of view were an electronic clock and an LED display, enabling the exposure time and active transducer to be simultaneously recorded with the pulse-echo trace from the oscilloscope display.

\section{Stereo Camera System}

Two $70 \mathrm{~mm}$ cameras mounted in the nose of the aircraft (see figure 3 ) were used to photograph the ice accretion on the wing cuff. These photographs were later photogrammetrically analyzed to obtain a profile of the ice shape (a detailed description of the stereo camera system and the associated image analys is is contained in reference 12). The ice surface can typically be resolved to with in $+1-0.03$ in. from these stereo image pairs. However adequate photographs of the ice accretion can only be obtained when the aircraft is in clear air, and hence the stereo camera system cannot provide ice growth data while the aircraft is in the icing cloud.

\section{Procedure}

Since the wing cuff was exposed throughout each flight, the ultrasonic array system was activated from take-off to landing. The multiplexing rate on the pulser/receiver was typically adjusted to allow four complete scans of the array per minute. This multiplexing rate provided frequent ice thickness measurements from each transducer, while still enabling time variations in each echo signal to be observed. As discussed earlier, time variations in the echo signal are used to distinguish the presence of liquid water on the ice surface, and bence to determine if the ice growth is wet or dry.

The ambient icing conditions (temperature, cloud liquid water content, droplet size distribution etc.) were recorded throughout each flight by the aircraft's on-board icing instrumentation. Stereo photograph pairs of the iced wing cuff were also taken during each encounter. However since these photographs could only be obtained outside the icing cloud, the time interval between successive photographs was generally long (10-30 minutes). Typically one or two stereo photograph pairs were taken per encounter.

Since the wing cuff was not de-iced, it was usually possible to mechanically measure the final ice shape (using vernier calipers) after landing. Nine research flights were conducted with the ultrasonic array system between February and March 1986.

\section{Results}

Ice growth measurements for three research flights $(86-31,86-32$ and $86-33)$ are presented in this section. Table 1 summarizes the time-averaged icing conditions during each of the three flights.

\section{Flight $86-31$}

Figure 5 illustrates the final ice shape accreted on the wing cuff at the completion of flight 86-31. Three separate measurements of the final ice profile are shown. The open circles represent thickness readings obtained from the stereo photograph analysis, while the crosses indicate measurements made with vernier calipers after landing. The final ultrasonic ice thickness measurements (from transducers $C, D, E$ and $F$ ) are shown as a solid line on the figure. The agreement between all three of these independent measurements is within $0.5 \mathrm{~m}$, with a final ice thickness of approximately $9 \mathrm{~mm}$ indicated. The accretion rate throughout the hour long encounter was low (due to the low cloud liquid water content), and as a result the final accretion is only moderately thick. The relatively large droplet sizes encountered, however, resulted in wide droplet impingement imits and hence the final accretion extends over most of the leading edge.

Due to the cold temperature and low liquid water contents encountered (see Table 1), dry or rime ice growth was observed throughout flight 86-31. Under these conditions, the impinging cloud droplets freeze on impact, and the final ice shape is seen to have a profile similar to that of the leading edge, and does not display the horns characteristic of glaze ice growth. This type of conformal ice shape is typical of moderate thickness rime ice accretions.

\section{- Stereo Photograph Measurement}

$\times$ Mechanical Measurement (Verniers)

Final Ultrasonic Measurement
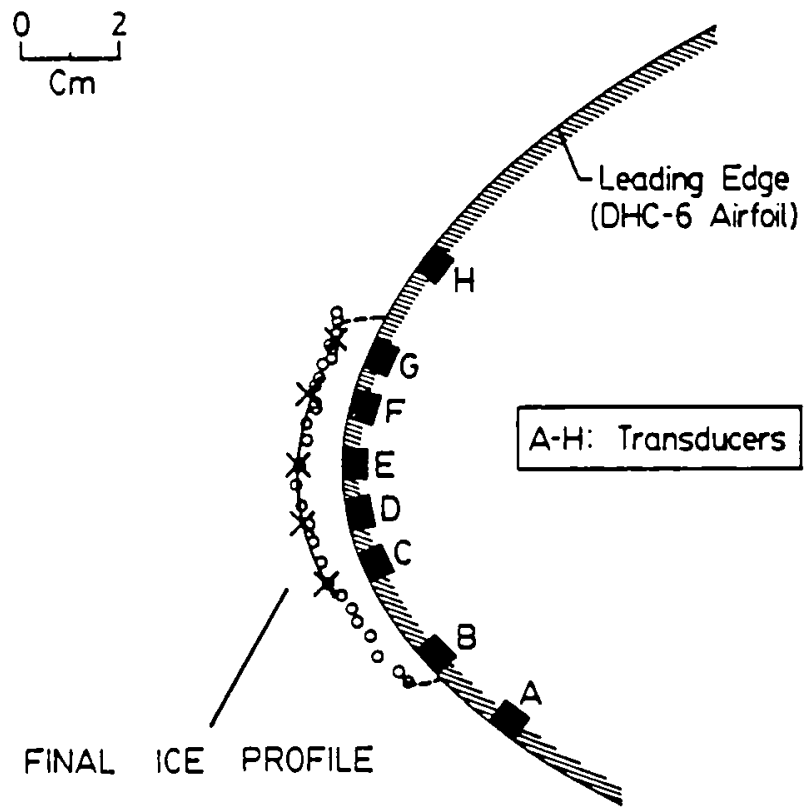

Fig. 5 Final ice profile for flight 86-31. 


\begin{tabular}{|lr|rrr|}
\hline Flight Number & & $86-31$ & $86-32$ & $86-33$ \\
\hline Flight Duration & (minutes) & 66 & 58 & 57 \\
Altitude & (feet) & 7603 & 4336 & 4068 \\
Airspeed & (knots) & 138 & 134 & 129 \\
Static Temperature & $\left({ }^{\circ} \mathrm{C}\right)$ & -10.0 & -6.3 & -5.8 \\
Liquid Water Content $\quad\left(g / \mathrm{m}^{\wedge} 3\right)$ & 0.06 & 0.16 & 0.26 \\
Median Volume Diameter (microns) & 15.0 & 14.3 & 13.0 \\
\hline
\end{tabular}

Table 1 Time-averaged flight and ambient atmospheric icing conditions.

Figure 6 is a plot of ice thickness, measured by the array transducers, versus time during flight 86-31. Each thickness measurement represents the average ice thickness over the transducer beam area, i.e. over a 0.25 in. diameter area. Also shown in the figure is the cloud liquid water content (measured by a Johnson-williams hot-wire probe) during the flight. From the figure it can be seen that both the cloud liquid water content and the ice growth rate vary during the encounter.
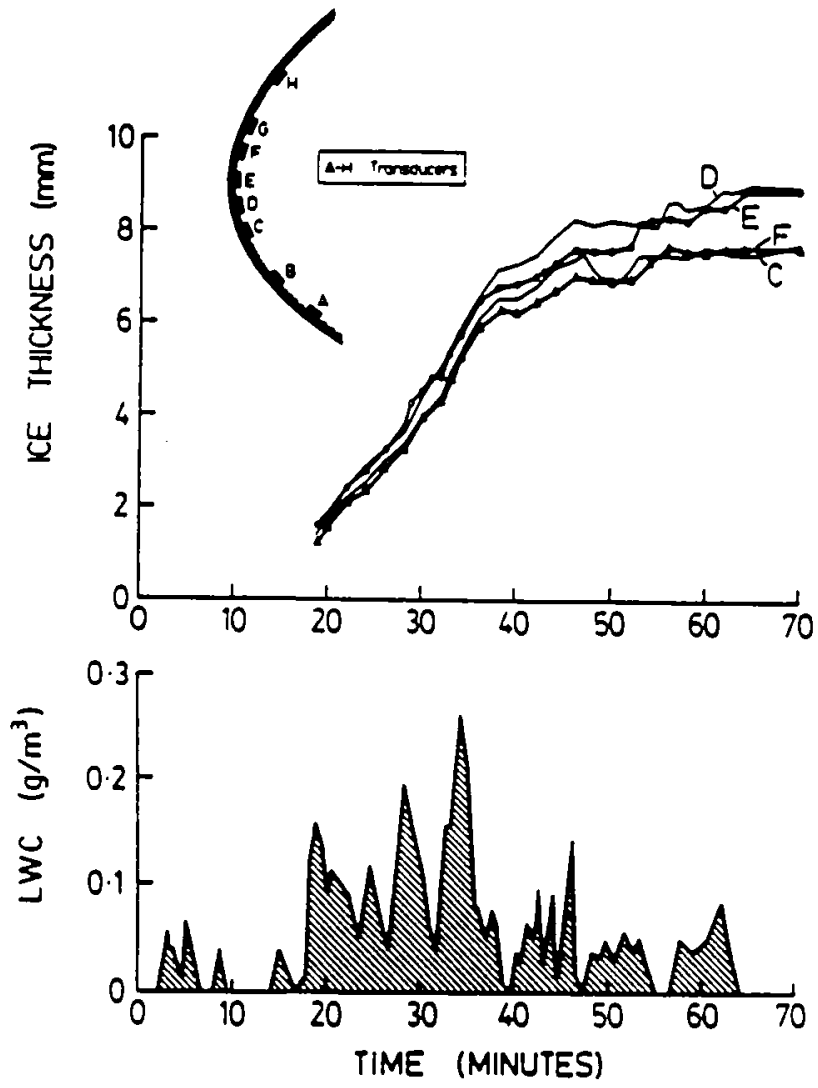

Fig. 6 Ultrasonically measured ice thickness and cloud liquid water content vs. time for flight $86-31$.

Since dry ice growth was observed throughout the flight (as indicated by the ultrasonic echo characteristics from the ice surface), the accretion rate is expected to be proportional to the cloud liquid water content. Therefore fluctuations in the cloud liquid water content will produce similar variations in the ice accretion rate. Figure 6 clearly shows this coupling between cloud liquid water content fluctuations and changes in the ice accretion rate. For example, as a result of the decrease in average liquid water content during the latter part of the flight, the measured growth rates during the last half hour of the flight are significantly lower than those for the first 40 minutes. Shorter time-scale coupling of the cloud liquid water content and ice growth rate is also apparent. For example, the high LWC spike occuring after 35 minutes produces a noticeable increase in the accretion rates at that time.

From figure 6 it can be seen that the ice thickness over the central transducers, $D$ and $E$, was consistently greater than that over transducers $F$ and $C$ at either side. This spatial variation in ice thickness is due to the higher local collection efficiency near the center of the accretion (transducers $D$ and $E$ ), than towards the edges (transducers $C$ and $F$ ).

Figure 7 shows the ultrasonically measured ice growth during flight 86-31 in the form of successive ice profiles. These profiles were constructed by fairing a curve through the "point" thickness measurements from the array transducers. A total of six profiles are shown, with six minutes between each profile. The time at which the profiles were measured is indicated on the lower plot of the cloud liquid water content during the flight.

The ultrasonically measured profiles show the ice shape to be relatively conformal to the leading edge throughout the encounter. Thickness measurements from transducers 8 and $G$, located near the edges of the accretion, were not possible after the second profile. This was because the slope of the ice surface above these transducers, relative to the airfoil surface, became too large, reflecting the return echo away from the transducer and significantly reducing the received echo strength. Increasing the receiver gain in this situation would alleviate this problem; however, varying the receiver gain between transducers was not practical with the single multiplexed pulser/receiver used for these tests. Since a single "optimum" gain had to be used, this "edge" effect dropout of the echo signal was often unavoidable. 

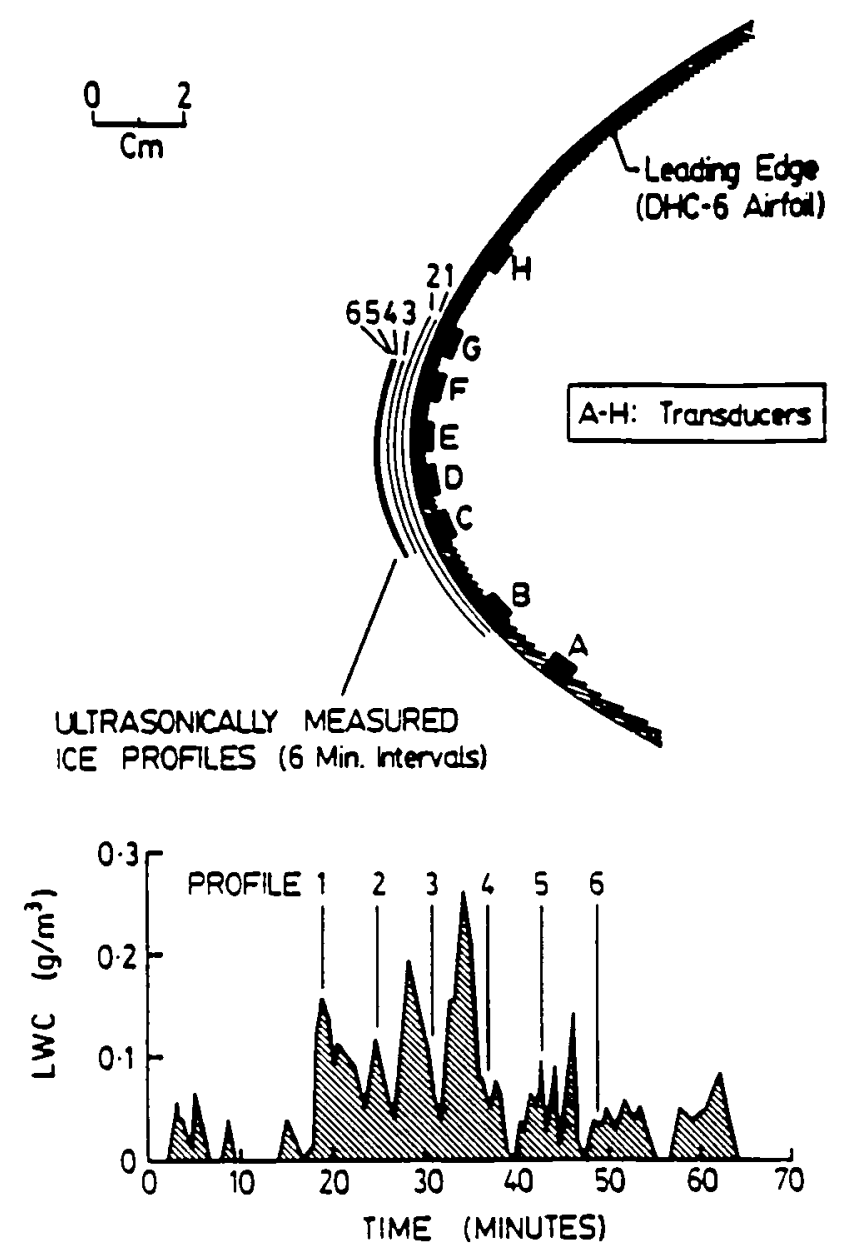

Fig. 7 Ultrasonically measured ice profiles for flight 86-31.

The ice profiles in figure 7 again illustrate the non-uniform growth rate throughout the encounter. The first three profiles all show approximately equal growth, corresponding to the roughly constant average liquid water content during this period. The higher liquid water content in the interval between profiles 3 and 4 results in more growth, as evidenced by the larger profile spacing. Following profile 4 the liquid water content falls, and as a result profiles 5 and 6 show little further growth.

Figure 8 is a comparison of the experimentally measured ice growth during flight 86-31 with that predicted by an analytical icing code (LEWICE). The time-averaged icing conditions for the flight (see Table 1) were used as input conditions for the code, and ice growth was computed at six minute intervals.

As discussed earlier, the cold cloud temperature and low liquid water contents encountered produced dry ice growth throughout the flight, and the analytical code correctly predicted dry-growth for the duration of the simulation. Because the impinging droplets freeze on impact for dry growth, no local energy balance is required and the analytical code is reduced to a time-stepped calculation of the potential flowfield and local collection efficiency. Both flowfield and droplet trajectory calculations are well understood, and the agreement between the final analytical and experimental ice shapes is good, with both the impingement limits and final thicknesses approximately equal.

The constant icing conditions used by the analytical code do however result in predictions of essentially constant growth rate at each point around the leading edge. Experimentally the growth rate is observed to fluctuate with the varying cloud liquid water content. Since dry ice growth was observed throughout this encounter, these variations in the natural icing conditions affected only the amount of growth between each profile. However, under different ambient conditions, fluctuations in the cloud liquid water content may result in transitiog between dry and wet ice growth during an encounter. In this case the use of a single, time-averaged liquid water content as input to an analytical code will not accurately model the icing process.
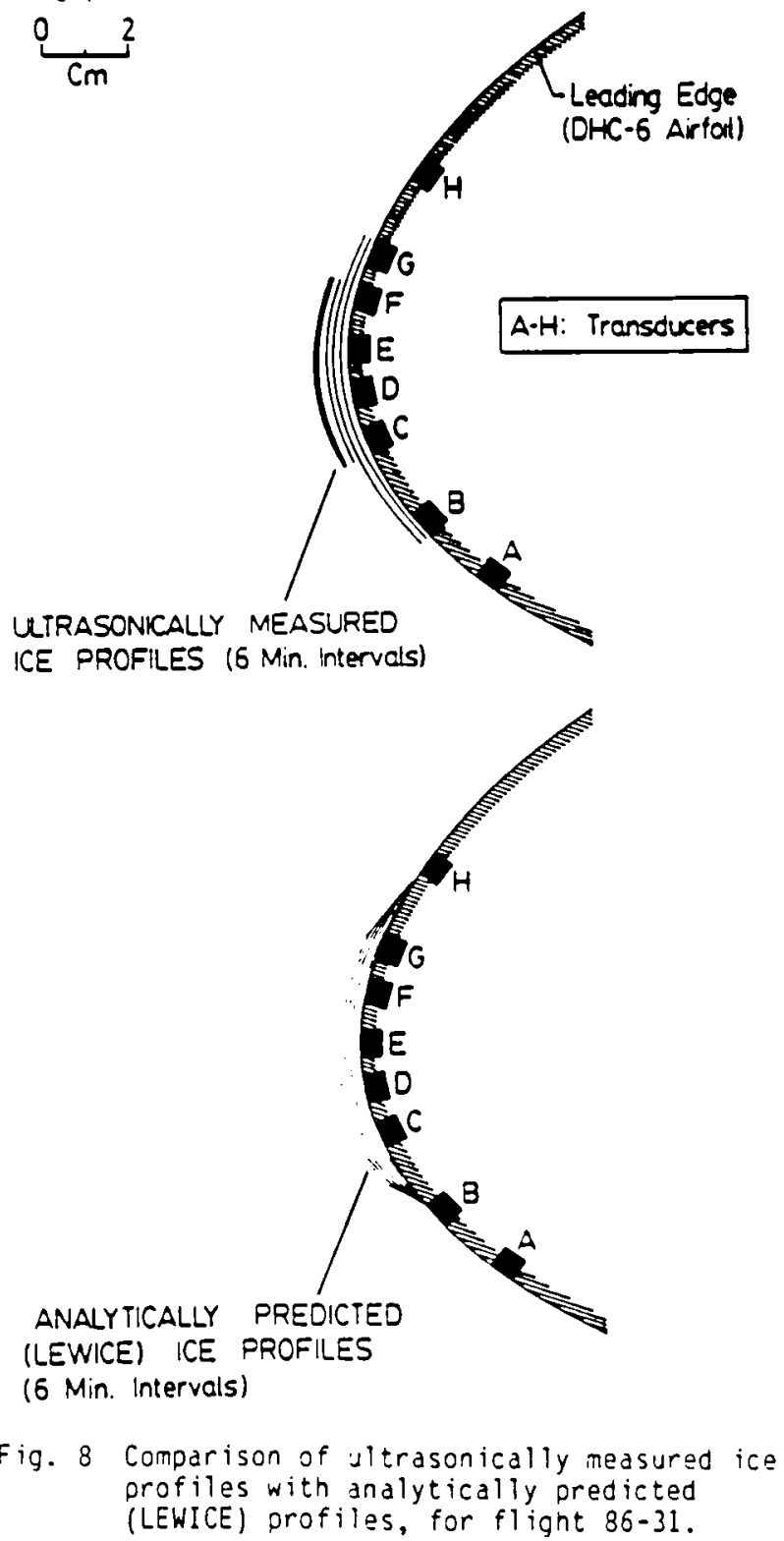

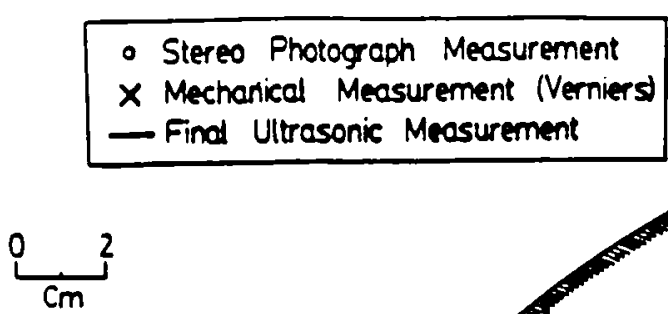

FINAL ICE PROFILE

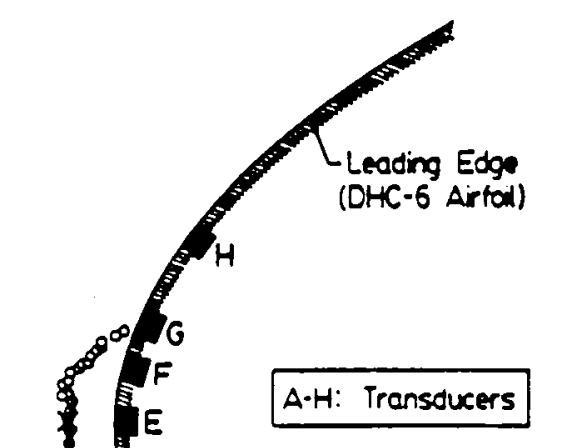

A-H: Transoducers

ULTRASONICALLY MEASUREO

ICE PROFILES (6 Min. Intervals)
Flight $86-32$

Figure 9 summarizes the experimentaliy measured ice growth for flight 86-32. The final ice shape, obtained from stereo photograph, ultrasonic and vernier cal iper measurements, is shown. The agreement between these thickness measurements is again within $0.5 \mathrm{~mm}$. Also shown in the figure are the ultrasonically measured ice growth profiles and the cloud liquid water content during the flight.

Ory ice growth was observed throughout the encounter, and the ice shape is always fairly conformal to the leading edge, as observed for flight 86-31. However, the ice accretion formed during flight 86-32 does not cover as much of the leading edge as the accretion for flight 86-31, due to the smalier droplet sizes encountered during flight 86-32 (see Table 1). Variations in the ice growth rate are clearly iliustrated by the profile spacing, and again are due to the varying cloud liquid water content. The loss of signal from transducer $C$ towards the end of the flight was due to the slope of the ice/air interface at the edge of the accretion.

\section{Flight $86-33$}

As a final illustration, the ice growth during flight $86-33$ is presented in figure 10 .

Experimental difficulties with the oscilloscope display prevented ultrasonic thickness measurements from being recorded for the entire encounter; hence, there are no final ultrasonic measurements of the ice shape. However it is interesting to observe that although the final profile displays a deep depression near the stagnation region, the initial ultrasonically measured profiles do not show any depression developing early in the encounter. Ory ice growth was indicated by the ultrasonic echo characteristics for the first 18 minutes of the encounter, and the depression may have formed as a result of wet ice growth later in the flight.

A computer simulation of this encounter was performed using the LEWICE analytical icing code, and the predicted ice growth is shown in figure is along with the final ice profile from the stereo photograph analysis. The time-averaged icing conditions for the flight were again used as input for the code, and ice profiles were computed at one minute intervals.

The analytically predicted ice shape displays a similar depression in the stagnation region to that observed experimentally. However using the steady time-averaged icing conditions, the analytical nodel predicts wet ice growth throughout the encounter, while dry ice growth was initially observed from the ultrasonic echo characteristics. The analytical code also predicts significant ice accretion due to liquid runback over transducers $G$ and $H$, al though experimentally no runback accretion was observed over these transducers.

These discrepancies between experimentally observed ice growth in fluctuating icing conditions, and analytically predicted growth for steady icing conditons, highlight the need for more experimental measurements of the ice accretion process, particularly during wet or glaze ice growth. 

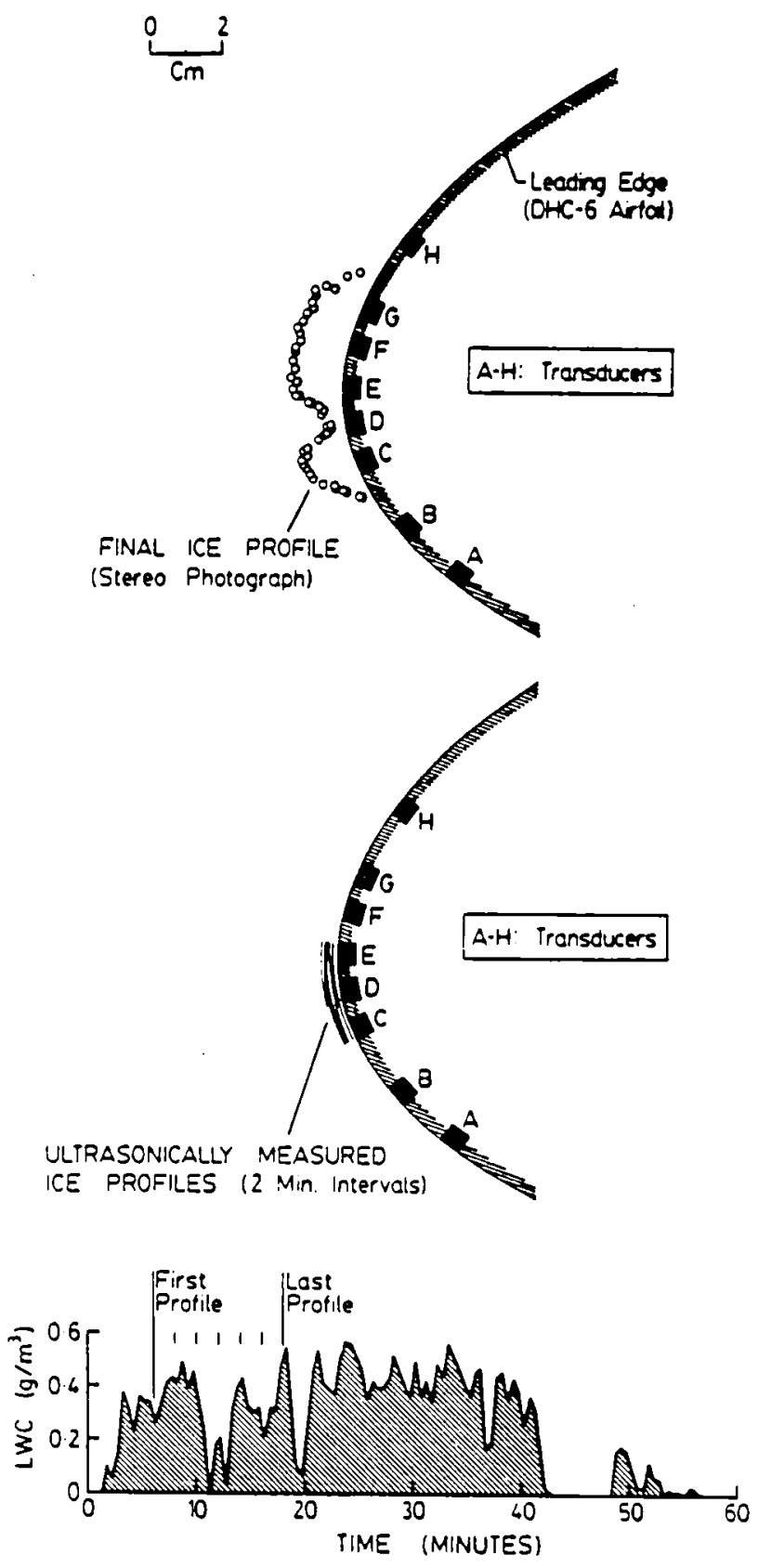

Fig. 10 Final ice profile and ultrasonically measured ice profiles (incomplete), for flight $86-33$.

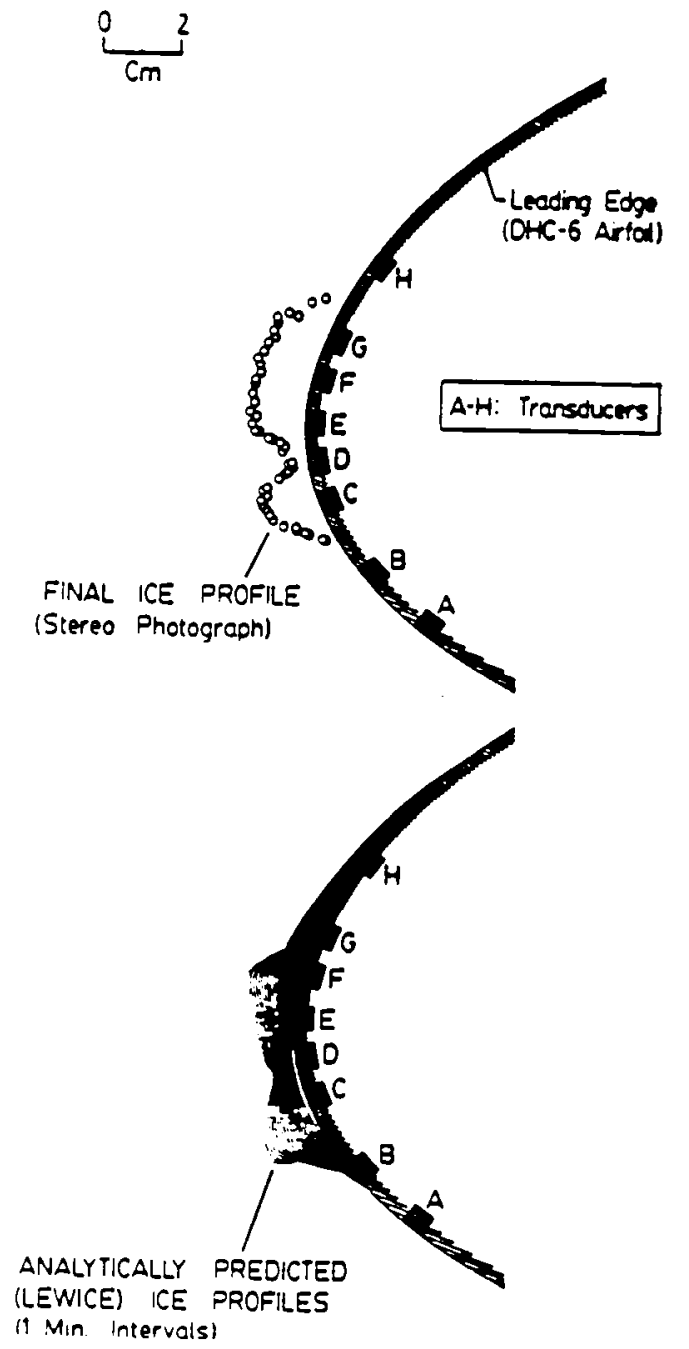

Fig. 11 Comparison of final ice profile from stereo photograph analys is with analytically predicted ice profiles (LEWICE), for flight 86-33.

\section{Conclusions}

Experimental measurements of ice growth as a function of time can provide a valuable tool for icing research. These measurements allow the evolution of the ice shape and the underlying physical processes to be studied, as well as permitting quantitative comparisons of flight and wind tunnel icing results. Initial tests using an array of ultrasonic transducers have shown the following:

Ultrasonic pulse-echo techniques may be used to measure ice thickness over a small area on a body to within $0.5 \mathrm{~mm}$.

Thickness measurements from an array of ultrasonic transducers can be used to provide a profile of the ice shape. By repeatedly scanning the array, the ice profile can be measured as a function of time during the icing encounter. 
Ice growth rates measured during flight ic ing conditions are typically not constant. For dry ice growth the accretion rate varies with the cloud liquid water content.

At the edges of the accretion, the ultrasonic echoes are significantly weakened due to the slope of the ice surface relative to the airfoil surface. Accurate ultrasonic thickness measurements are difficult in these cases and additional shape measurements, for example from stereo photographs of the ice accretion, can be used to provide good edge definition.

Differences between experimentally measured ice growth and analytically predicted growth underscore the need for a better understanding of the effects of varying ambient icing conditions, particularly when wet ice growth is involved.

Despite the prel iminary nature of these tests, and the limited range of icing conditions encountered, the results presented illustrate the value of experimental measurements of ice growth. Further tests in both flight and wind tunnel icing conditions will aid the development of more detailed analytical icing models as well as documenting differences between flight and wind tunnel icing results.

\section{Acknowledgments}

This work was supported by the National Aeronautics and Space Administration and the Federal Aviation Administration under Grants NGL-22-009-640 and NAG3-666. Flight test facilities were provided by the NASA Lew is Research Center. The assistance of Patrick L. Cassady during the stereo photography analys is is gratefully acknowledged.

\section{References}

1. MacArthur, C.O., "Numerical Simulation of Airfoil Ice Accretion," AIAA 83-0112, January 1983.

2. Lozowski, E.P., Stallabrass, J.R., and Hearty, P.F., "The Icing of an Unheated Non-Rotating Cylinder in Liquid Water Droplet-Ice Crystal Clouds," National Research Council of Canada (NRC) Report LTR-LT-86, February 1979.

3. Bragg, M.8., Gregorek, G.M., and Shaw, R.J., "An Analytical Approach to Airfoil ICing," AIAA 81-0403, January 1981.

4. Ruff, G.A., "Development of an Analytical Ice Accretion Prediction Method (LEWICE)," Sverdrup Technology, Inc., LeRC Group Progress Report, February 1986.

5. Personal communication with W.A. OIsen, NASA Lewis Research Center, Cleveland, OH, March 1986.

6. Hansman, R.J., and Kirby, M.S., "Comparison of Wet and Ory Ice Growth in Artificial and Fi ight Icing Conditions," Journal of Thermophysics and Heat Transfer, to be published Aprif 1987.
7. Hansman, R.J., and Kirby, M.S., "Measurement of Ice Accretion Using Ultrasonic Pulse-Echo Techniques," Journal of Aircraft. Vol. 22, June 1985, pp. $530-535$.

8. Hansman, R.J., and Kirby, M.S., "Measurement of Ice Growth During Simulated and Natural Icing Conditions Using Ultrasonic Pulse-Echo Techniques," Journal of Aircraft, Vol. 23, June 1986, pp. 492-498.

9. Ide, R.F., and Richter, G.P., "Evaluation of Icing Cloud Instruments for 1982-83 Ic ing Season Flight Program," AIAA 84-0020, January 1984.

10. Mikkelsen, K.L., Mcknight, R.C., Ranaudo, R.J., and Perkins, P.J., "ICing Flight Research: Aerodynamic Effects of Ice and Ice Shape Documentation With Stereo Photography," AIAA 85-0468, January 1985.

11. Personal communication with R.C. MCKnight, NASA Lewis Research Center, Cleveland, OH, November 1985.

12. Mcknight, R.C., Palko, R.L., and Humes, R.L., "In-Flight Photogrammetric Measurement of Wing Ice Accretions," NASA TM-87191, January 1996. 